\title{
A EDUCAÇÃO AMBIENTAL NO ENSINO: INVESTIGANDO AS ABORDAGENS, PERCEPÇÕES E DESAFIOS NA REALIDADE DE UMA ESCOLA PÚBLICA EM RIO GRANDE (RS)
}

\author{
Vilmar Alves Pereira ${ }^{1}$ \\ Caroline de Azevedo Gibbon ${ }^{2}$
}

RESUMO: A Educação Ambiental (EA) se destaca por sua importância no ensino e por suas implicações na formação de educandos conscientes. Assim sendo, os objetivos desse trabalho são compreender como a EA é abordada no ensino; perceber se são tecidas relações entre a $E A$, a realidade dos educandos e os conteúdos escolares; e entender como a EA pode servir como aspecto desencadeador para uma tomada de consciência. $O$ estudo foi desenvolvido através de revisão bibliográfica e pesquisa de campo realizada com educadores e educandos de uma escola em Rio Grande - RS. Os resultados expressam as concepções de meio ambiente dos sujeitos da pesquisa, a opinião dos educandos em relação ao estudo de temas relacionados ao meio ambiente e o reconhecimento dos educadores quanto à relevância da EA.

Palavras-chave: Educação Ambiental; Educadores; Educandos; Ensino.

1Universidade Federal do Rio Grande. E-mail: vilmar1972@gmail.com 2 Universidade Federal do Rio Grande. E-mail: carolgibbon@hotmail.com ambiental Revbea, São Paulo, V. 9, N² 2: 376-394, 2014. 


\section{Introdução}

Dentre as temáticas mais discutidas na escola atual, a Educação Ambiental (EA) se destaca por sua importância no ensino de todas as disciplinas e por suas implicações na formação de educandos conscientes. No entanto, é necessário realizar algumas indagações: como a EA é realmente abordada no ambiente escolar? São tecidas relações entre EA e os conteúdos escolares na prática? Como os alunos procedem diante de tais práticas que envolvam sua atuação cidadã frente às temáticas socioambientais?

$\mathrm{Na}$ perspectiva de avaliar as questões ambientais tratadas no ensino, objetivamos compreender como e quando a educação ambiental é abordada no ensino das diversas disciplinas (português, matemática, ciências, história e geografia); perceber se são tecidas relações entre a educação ambiental, a realidade vivida pelos educandos da escola em questão e os conteúdos escolares; e discernir em que medida a educação ambiental pode servir como aspecto desencadeador para uma tomada de consciência e de novas atitudes.

A natureza há muito tempo está exposta aos constantes impactos causados pelo homem: poluição, desmatamento, queimadas, consumo insustentável, guerras, uso exacerbado de recursos esgotáveis, destruição de habitats, entre outros. Todas essas ações inconscientes têm trazido inúmeras consequências ao meio ambiente, com isso, é indispensável que toda a humanidade repense suas atitudes. Portanto, atualmente, tem se tornado essencial à utilização da educação para despertar a consciência dos educandos quanto às questões ambientais. Assim a EA tem sido uma forma de repensarmos nossas atitudes enquanto seres planetários, contribuindo para construção e reconstrução de conhecimentos e valores, e para a formação de cidadãos críticos e conscientes, que se considerem seres pertencentes à natureza e não exploradores dessa, logo, tratem com respeito todas as formas de vida. Mesmo assim, nota-se que EA se efetiva, na maioria das vezes, de maneira ineficiente no ensino. Esses são consequentemente os aspectos motivadores do presente estudo.

Nesse momento, defendemos as seguintes hipóteses: compreendemos que a EA é um tema de real importância na construção de conhecimentos e na formação de cidadãos conscientes, logo, deve ser percebida dessa forma pelos educadores; acreditamos que a abordagem da EA sugerida pelos Parâmetros Curriculares Nacionais (PCN), como tema transversal que permeia todas as disciplinas, possibilita sua maior discussão e contribui para a construção de uma aprendizagem significativa; pensamos que a visão dicotômica entre ser humano e ambiente se faz presente no âmbito escolar; entendemos que os educandos têm gosto pelo estudo de temas relacionados ao meio ambiente e a sua preservação, e logo, se tornam pessoas mais preocupadas com o planeta em que vivem.

O estudo foi desenvolvido em dois momentos: revisão bibliográfica e pesquisa de campo realizada na E.E.E.M. Carlos Loréa Pinto, na cidade do Rio 
Grande, através de questionários semiestruturados, para educadores da escola e para educandos de uma turma de 6⿳亠丷厂 série do ensino fundamental.

\section{Compreensões de Educação Ambiental}

De acordo com Reigota, nas primeiras décadas do surgimento da Educação Ambiental (1960, 1970 e 1980), um argumento muito presente para explicar a escassez dos recursos naturais era atribuído ao crescimento populacional. Depois de muitas discussões vindas principalmente de pesquisadores de países de "terceiro mundo", percebeu-se que na verdade ocorria um excessivo consumo dos recursos naturais por uma pequena parcela da população mundial referente aos países industrializados. Outro argumento evidente era de relacionar intimamente a Educação Ambiental com a preservação da flora e da fauna, se tornando praticamente sinônimo da ecologia biológica, e se afastando cada vez mais dos aspectos sociais e políticos que provocavam os danos à biodiversidade natural.

Hoje está claro que a Educação Ambiental não se relaciona apenas com os aspectos biológicos da vida, embora tenham tamanha importância e mereçam atenção garantida, há também um grande comprometimento com as questões políticas e sociais:

Quando afirmamos e definimos a educação ambiental como educação política, estamos afirmando que o que deve ser considerado prioritariamente na educação ambiental é análise das relações políticas, econômicas, sociais e culturais entre a humanidade e a natureza e as relações entre os seres humanos. (...) A educação ambiental como educação política está comprometida com a ampliação da cidadania, da liberdade, da autonomia e da intervenção direta dos cidadãos e cidadãs na busca de soluções e alternativas que permitam a convivência digna e voltada para o bem comum (REIGOTA, 2009, p.13).

Carvalho (2006) também diz que a Educação ambiental surgiu num terreno marcado por uma tradição naturalista, na qual o meio ambiente é sinônimo de "natureza", "vida biológica", "vida selvagem", "flora e fauna", desconsiderando todas as interações entre seres humanos e natureza que muitas das vezes constituem-se relações enriquecedoras ao meio ambiente, como no caso dos extrativistas, ribeirinhos e povos indígenas. Declara ainda que para transcender essa marca, é necessária a afirmação de uma visão socioambiental, visando à superação da dicotomia entre natureza e sociedade:

A visão socioambiental orienta-se por uma racionalidade complexa e interdisciplinar e pensa 0 ambiente não como

Revbea, São Paulo, V. 9, № 2: 376-394, 2014. 
sinônimo de natureza intocada, mas como um campo de interações entre a cultura, a sociedade e a base física e biológica dos processos vitais, no qual todos os termos dessa relação se modificam dinâmica e mutuamente. Tal perspectiva considera o meio ambiente como espaço relacional, em que a presença humana, longe de ser percebida como extemporânea, intrusa ou desagradora ("câncer do planeta"), aparece como agente que pertence à teia de relações da vida social, natural e cultural e interage com ele (CARVALHO, 2006, p. 37).

Há também uma grande confusão conceitual em relação ao termo meio ambiente, que está constantemente presente nos meios de comunicação, nos conteúdos escolares e nos livros didáticos. No entanto, mesmo permeando nosso cotidiano, muitos ainda não têm clareza de seu significado e tão pouco reconhecem sua complexidade. Para Reigota o meio ambiente não é apenas sinônimo de meio natural, definindo-o como:

[...] um lugar determinado e/ou percebido onde estão em relação dinâmica e em constante interação os aspectos naturais e sociais. Essas relações acarretam processos de criação cultural e tecnológica e processos históricos e políticos de transformações da natureza e da sociedade (REIGOTA, 2009, p.36).

Entretanto, não existe um consenso nas definições de meio ambiente, cada pessoa apresenta sua definição a partir de suas percepções. De acordo com o autor acima citado, para realizar a Educação Ambiental é necessário primeiramente conhecermos as definições de meio ambiente dos sujeitos envolvidos. Assim é possível dialogar sobre as diversas definições e construir juntos uma definição mais adequada para se abordar a problemática que se queira conhecer e tentar resolver.

É necessário ressaltar ainda, que há um grande questionamento em torno do uso do termo ambiental em educação, pois afinal existe algum tipo de educação que não ocorra em um ambiente? No entanto, seu uso é explicado por Loureiro:

Talvez o uso indiscriminado do adjetivo "ambiental" não só na educação contribua pouco para resolver a confusão, ou até gere outros níveis de incompreensão, contudo, seu uso se justifica à medida que serve para destacar dimensões "esquecidas" pelo fazer educativo, no que se refere ao entendimento da vida e da natureza, e revelar ou denunciar as dicotomias da modernidade capitalista e da ciência cartesiana e positivista (esfera econômica-esfera social; sociedadenatureza; mente-corpo; matéria-espírito) (LOUREIRO, 2006, p. 34). 
Outro fato a ser destacado é o estreito vínculo entre as questões referentes à ética e a educação ambiental. Uma vez que sua compreensão e presença na vida cotidiana têm sido ampliadas por educadores e educadoras ambientais quando enfatizam o respeito a todos os seres vivos, a igualdade e o respeito às diferenças étnicas, culturais e sexuais, e quando se mantêm contra qualquer tipo de corrupção, privilégios e violência. Infelizmente, as relações sociais e políticas em nosso país, se tornam cada vez mais carentes dessa essencial e valiosa ética:

A possibilidade de se levar vantagem em qualquer situação é o clichê básico predominante, e em muitas ocasiões isso é entendido como natural. (...) Com base no pensamento político, filosófico, cultural e pedagógico contemporâneo, que caracteriza a educação ambiental como educação política, podemos afirmar que não há nada de natural na competição, oportunismo, má-fé, ganância e outros termos que na vida cotidiana possibilitam a permanência de privilégios de poucos (REIGOTA, 2009, p. 16 e 17).

E dentre os princípios éticos da educação ambiental, cabe salientar o aniquilamento do pensamento antropocêntrico, o qual considera o ser humano o ser mais importante da Terra, o centro do universo, trazendo um grande distanciamento entre humanidade e natureza:

O ser humano contemporâneo vive profundas dicotomias. Dificilmente se considera um elemento da natureza, mas um ser à parte, como um observador/explorador dela. (...) Desconstruir essa noção antropocêntrica é um dos princípios éticos da educação ambiental (REIGOTA, 2009, p 16).

Precisamos romper com esse pensamento, visto que a população humana representa apenas uma espécie dentre os milhões de outras existentes em nosso planeta. Não somos os donos do mundo e tão pouco somos mais importantes que outros seres para a manutenção do equilíbrio da Biosfera. Logo, esse princípio merece atenção principalmente nas práticas relacionadas à $E A$.

Todavia, com o agravamento atual da crise ambiental, sabe-se que a Educação Ambiental tem muito a contribuir para o estabelecimento de uma relação harmônica entre os seres humanos e entre a humanidade e a natureza, garantindo a possibilidade de se viver dignamente: 
A educação ambiental deve procurar favorecer e estimular possibilidades de se estabelecer coletivamente uma "nova aliança" (entre seres humanos e natureza e entre nós mesmos) que possibilite a todas as espécies biológicas (inclusive a humana) a sua convivência e sobrevivência com dignidade (REIGOTA, 2009, p.14).

Além disso, participação dos cidadãos e cidadãs é indispensável para a tomada de atitudes que desencadeiam a resolução dos problemas, que a princípio parecem locais, no entanto, devido às relações entre as comunidades do mundo, as alternativas tomadas em seu cotidiano podem instigar resultados consideráveis:

Claro que a educação ambiental por si só não resolve os complexos problemas ambientais planetários. No entanto, ela pode influir decisivamente para isso, quando forma cidadãos e cidadãs conscientes dos seus direitos e deveres. Tendo consciência e conhecimento da problemática global e atuando na sua comunidade e vice-versa haverá uma mudança na vida cotidiana que, se não é de resultados imediatos, visíveis, também não será sem efeitos concretos (REIGOTA, 2009, p. 18 e 19).

Contudo, temos clara convicção de que a educação ambiental sozinha, não será em nenhum momento a salvação planetária. Porém, o lema ecológico "Pensamento global e ação local, ação global e pensamento local", expressa a influência das ações e decisões mundiais sobre as realidades locais, e também reflete a importância dos "cidadãos e cidadãs do mundo atuarem em suas comunidades. Exemplificando uma luta social local que adquiriu dimensões ecológicas, apoiada internacionalmente, foi a luta dos seringueiros da Amazônia, liderados por Chico Mendes.

Podemos compreender então, que os problemas ambientais foram criados por homens e mulheres e por eles devem ser solucionados, o papel da Educação Ambiental como sendo educação política, social e ecológica é mediar essas relações, orientando-se para a comunidade e auxiliando o cidadão e a cidadã a participarem da resolução dos problemas e da busca de alternativas no seu cotidiano de realidades específicas.

\section{Percursos da Educação Ambiental no Brasil}

Para iniciar, é necessário ressaltar a posição brasileira na Conferência Mundial de Meio Ambiente Humano, realizada pela Organização das Nações Unidas, no ano de 1972, em Estocolmo, Suécia. Nosso país se posicionou coerentemente com o modelo econômico de saque aos recursos naturais em 
virtude do desenvolvimento apoiado no sistema político ditatorial-tecnocrático que governou o Brasil entre as décadas de sessenta a oitenta:

[...] a Organização das Nações Unidas realizou em 1972, em Estocolmo, Suécia, a Primeira Conferência Mundial de Meio Ambiente Humano. O grande tema em discussão nessa conferencia foi a poluição ocasionada principalmente pelas indústrias. O Brasil e a Índia, que viviam na época "milagres econômicos", defenderam a idéia de que a "poluição é o preço que se paga pelo progresso" (REIGOTA, 2009, p. 25).

É um tanto quanto revoltante pensar a posição do país nessa Conferência, abrindo mão de todas as consequências que viriam em decorrência de tanta poluição em troca de progresso e abrindo suas portas para instalação de indústrias multinacionais poluidoras impedidas de operarem nas mesmas condições em seus países de origem. Não é sem razão que Cubatão foi considerada pela ONU em 1980 a cidade mais poluída do mundo, e devido à grande concentração de poluidores químicos, muitas crianças nasceram acéfalas. Também não foi por coincidência que a Amazônia atingiu índices alarmantes de desmatamento.

Nos diz Loureiro (2006), que a Educação Ambiental se fez tardiamente no Brasil, pois ainda que registros mostrem a existência de programas e projetos desde a década de setenta, é durante a década de oitenta que esta começa a ganhar dimensões públicas relevantes, devido principalmente a sua inclusão na Constituição Federal de 1988. Outro marco nacional ocorreu em 1987, quando Conselho Federal de Educação define que a Educação Ambiental tem caráter interdisciplinar, oficializando a posição do governo a cerca do debate sobre a inserção da EA no ensino formal como uma disciplina ou não.

Mesmo na década de oitenta, era atribuído à Educação Ambiental um caráter político, estando comprometida apenas com a resolução dos problemas ambientais e com a preservação do patrimônio natural, não sendo tratada como parte da área da educação:

A falta de percepção da Educação Ambiental como processo educativo, reflexo de um movimento histórico, produziu uma prática descontextualizada, voltada para a solução de problemas de ordem física do ambiente, incapaz de discutir questões sociais e categorias teóricas centrais da educação (LOUREIRO, 2006, p. 81).

Da mesma forma que nos diz Carvalho (2006), afirmando que a Educação Ambiental surge primeiramente como uma inquietação dos movimentos ambientalista, assumindo em um segundo momento o caráter educativo: 
Assim, a EA é concebida inicialmente como preocupação dos movimentos ecológicos com uma prática de conscientização capaz de chamar a atenção para a finitude e má distribuição no acesso aos recursos naturais e envolver os cidadãos em ações sociais ambientalmente apropriadas. É em um segundo momento que a EA vai se transformando em uma proposta educativa no sentido forte, isto é, que dialoga com o campo educacional, com suas tradições, teorias e saberes (CARVALHO, 2006, p. 51 e 52).

Duas décadas após a Conferência de Estocolmo, foi realizada no Rio de Janeiro, a Conferência das Nações Unidas para o Meio Ambiente e Desenvolvimento, conhecida como Rio-92. Essa foi a primeira conferência das Nações Unidas aberta à sociedade civil, na qual cidadãos e cidadãs do mundo puderam participar e teve uma plena repercussão no país através da criação do Tratado sobre a Educação Ambiental para as Sociedades Sustentáveis:

Na sociedade brasileira, o evento não governamental da última década mais significativo para o avanço da EA foi o Fórum Global, que ocorreu paralelamente à Conferencia da ONU sobre Desenvolvimento e Meio Ambiente, no Rio de Janeiro, em 1992, conhecida como Rio-92. Nessa ocasião as ONGs e os movimentos sociais de todo o mundo reunidos no Fórum Global formularam o Tratado de Educação Ambiental para as sociedades sustentáveis, cuja importância foi definir o marco político para o projeto pedagógico da EA (CARVALHO, 2006, p. 53).

Outro acontecimento importante foi elaboração pelo Ministério de Educação, em 1997, dos Parâmetros Curriculares Nacionais (PCN) para o ensino fundamental. Nos PCN, o meio ambiente foi considerado um tema transversal, o que possibilitou uma fecunda discussão entre os educadores e as educadoras ambientais no Brasil:

Os Parâmetros Curriculares Nacionais, produzidos com base na LDB e lançados oficialmente em 15 de outubro de 1997, documento que definiu como temas transversais, em função da relevância social, urgência e universalidade: saúde, ética, pluralidade cultural, orientação sexual e meio ambiente. Apesar das críticas que recebeu pelo modo como pensou a transversalidade em educação (mantendo como eixos principais as disciplinas de conteúdos formais - português, matemática, ciências, historia e geografia) e pela baixa operacionalização da proposta, teve o mérito de inserir a temática ambiental não como disciplina e abordá-la articulada as diversas áreas de conhecimento (LOUREIRO, 2006, p. 83). 
Através dessa breve trajetória histórica da Educação Ambiental no Brasil, podemos perceber que apesar das contradições, ela constitui uma proposta pedagógica que tem construído uma perspectiva interdisciplinar para compreender as questões que afetam as relações entre sociedade e ambiente, e principalmente, intervir nessas relações, valorizando a diversidade das culturas e dos modos de compreensão do ambiente.

\section{Contextualização da Educação Ambiental no cotidiano escolar}

A educação ambiental deve estar presente em todos os espaços que educam cidadãos, sejam eles escolas, associações de bairro, parques, reservas ecológicas, sindicatos, universidade e nos meios de comunicação. No contexto da escola em meados dos anos 80, como já mencionado anteriormente, havia uma grande discussão sobre a educação ambiental se deveria se constituir como sendo uma disciplina ou não. No entanto, o Conselho Federal de Educação optou por considerar a EA como uma perspectiva de educação que deve permear todas as disciplinas.

Através da criação dos Parâmetros Curriculares Nacionais para a escola fundamental, em 1997, o meio ambiente foi considerado um tema transversal, que deve ser discutido por todas as disciplinas escolares. Os PCN foram muito criticados por sua proposta ter pouca susceptibilidade de ser colocada em prática, mas principalmente por considerar transversalidade como sinônimo de interdisciplinaridade. Reigota nos esclarece a diferença entre esses dois conceitos:

Esses dois conceitos são bem diferentes e implicam praticas pedagógicas com características diferentes. Numa breve explicação podemos dizer que uma pratica pedagógica interdisciplinar trabalha com o diálogo de conhecimentos disciplinares e que a transversalidade, pelo menos como foi definida pelos precursores, entre eles Félix Guatarri, não desconsidera a importância de nenhum conhecimento, mas rompe com a ideia de que os conhecimentos sejam disciplinares e que são validos apenas os conhecimentos científicos (REIGOTA, 2009, p. 42).

Entretanto, com todas as críticas e adesões aos PCN é necessário ressaltar que eles marcaram a Educação Ambiental brasileira, afinal, não há como negar a importância de incluí-la como integrante de todas as disciplinas:

A educação ambiental, como perspectiva educativa, pode estar presente em todas as disciplinas quando analisa temas que permitam enfocar as relações entre a humanidade e o meio natural e as relações sociais, sem deixar de lado as suas especificidades (REIGOTA, 2009, p. 45). 
No ensino da Educação Ambiental escolar é necessário priorizar o cotidiano dos educandos, para que percebam os principais problemas locais:

\begin{abstract}
$\mathrm{Na}$ educação ambiental escolar deve-se enfatizar o estudo do meio ambiente onde vive $o$ aluno e a aluna, procurando levantar os principais problemas cotidianos, as contribuições da ciência, da arte, dos sabres populares, enfim, os conhecimentos necessários e as possibilidades concretas para a solução deles (REIGOTA, 2009, p. 46).
\end{abstract}

No entanto, de acordo com Reigota, enfatizar o meio ambiente onde vive o educando, não significa que as questões ambientais distantes não devem ser exploradas, afinal não devemos esquecer que estamos procurando formar educandos com identidade e participação como cidadãos brasileiros e como cidadãos planetários.

Dentre os conteúdos escolares abordados pela EA, é necessário salientar que essa não se baseia em conteúdos específicos e tão pouco prioriza a transmissão de conceitos de disciplinas ou áreas do conhecimento: "O conteúdo mais indicado é aquele originado do levantamento da problemática ambiental vivida cotidianamente pelos alunos e pelas alunas e que se queira resolver" (REIGOTA, 2009, p.63).

Além disso, os conteúdos da EA procuram aproximar o aluno da ciência, mostrando não somente as problemáticas locais e também as relações mútuas entre o homem e o ambiente, mais sim aquelas que acontecem por todo mundo e permeiam todas as culturas: "O conteúdo da educação ambiental procura possibilitar ao aluno e a aluna as ligações entre a ciência, as questões imediatas $e$ as questões mais gerais, nem sempre próximas geográfica e culturalmente" (REIGOTA, 2009, p. 64).

Com isso, cabe ressaltar que a educação ambiental não é uma disciplina, mas sim uma perspectiva pedagógica e política que busca contribuir para a constituição de uma atitude ecológica, oferecendo um ambiente de aprendizagem social e individual no sentido mais profundo da experiência de aprender. Muito mais do que apenas se utilizar de conteúdos e informações, busca formar o sujeito humano, estabelecendo novos modos de ser, de compreender, de posicionar-se ante os outros e a si mesmo, enfrentando os desafios e as crises do tempo em que vivemos. 


\section{Investigando as práticas de Educação Ambiental no ensino em Rio Grande (RS)}

A partir desse momento, o estudo se focará na pesquisa de campo que foi realizada na Escola Estadual de Ensino Médio Professor Carlos Loréa Pinto. Esta se situa no bairro COAB IV, localizado na periferia da cidade do Rio Grande/RS.Esse bairro apresenta características de vulnerabilidade social, 0 que faz com que a comunidade escolar enfrente sérios problemas referentes às precárias condições de serviço de saúde, saneamento básico, iluminação, segurança, e, além disso, a escola vivencia a crescente evasão escolar dos educandos.

Mas, apesar dessas circunstâncias desfavoráveis, segundo o Plano Político Pedagógico, a escola visa o melhor para os seus alunos, buscando desenvolver o educando, assegurar-Ihe a formação comum indispensável para o exercício da cidadania e fornecer meios para progredir no trabalho e em estudos posteriores, procurando suprir as necessidades físicas, emocionais, espirituais e sociais.

A investigação da Educação Ambiental no ensino desta escola foi realizada a partir de uma abordagem qualitativa conforme Minayo (2011) através de questionários semiestruturados e da análise das narrativas dos sujeitos da pesquisa, que incluem nove educadores das diferentes disciplinas da escola e vinte e oito educandos da 6 $6^{\underline{a}}$ série do Ensino Fundamental.

Os educadores, em sua maioria, apresentam ensino superior completo. Para lecionarem na E.E.E.M Professor Carlos Loréa Pinto precisam se deslocar de outras localidades ou bairros da cidade, afinal não moram na comunidade de entorno. Além disso, possuem longas cargas horárias a cumprir e trabalham em mais de uma escola. Estes foram questionados quanto suas concepções de meio ambiente, a presença da Educação Ambiental em sua aula/escola e a relevância da abordagem de temas relacionados à Educação Ambiental para os alunos.

Os educandos sujeitos dessa pesquisa enfrentam dificuldades de aprendizagens, evasão escolar e altas taxas de repetência. Apresentam carência socioeconômica e cultural, no entanto, a amargura de uma vida sofrida não apagou o brilho dos seus olhos. São crianças incrivelmente carinhosas, receptivas, esforçadas e carismáticas. Muitos deles moram no bairro COAB IV, porém, a escola recebe alunos de no mínimo quatro bairros vizinhos. Durante a pesquisa, visualizaram imagens da comunidade de entorno e de outros locais da cidade que mostravam a degradação antrópica do meio ambiente. Depois disso, foram instigados quanto suas concepções de meio ambiente, suas opiniões a cerca da realidade explicitada pelas imagens, as atitudes que poderiam mudar ou tomar para reverter situações como as apresentadas pelas imagens e se gostam quando questões relacionadas ao meio ambiente são abordados nas aulas.

De acordo com as narrativas dos sujeitos da pesquisa, qualificaremos os apontamentos sobre Educação Ambiental no ensino em quatro temáticas: Revbea, São Paulo, V. 9, № 2: 376-394, 2014. 
concepções de meio ambiente; importância da abordagem da educação ambiental; percepções e medidas apontadas pelos educandos; e momentos e maneiras de abordar a educação ambiental. Almejando preservar a integridade física e moral dos educadores e educandos participantes dessa pesquisa, utilizaremos nomes fictícios.

\section{Concepções de meio ambiente}

Essa temática constitui a primeira questão da entrevista, sendo comum aos educadores e educandos. Quando questionado quanto suas considerações sobre meio ambiente, o educando João afirma que meio ambiente é "a vida dos seres vivos", a educanda Juliana considera que "o meio ambiente é tudo que o homem não tocou", discordando da educadora Joana que destaca "considero meio ambiente tudo que faz parte do universo terrestre desde o ar que respiramos até todo o tipo de sociedade existente".

A educanda Marina salienta "é todo o verde que está em nossa volta, os animais, as flores, as frutas, as árvores, portanto o meio ambiente é a natureza", da mesma forma, a educanda Luana considera "um lugar cheio de animais, cheio de árvores frutíferas e sem a presença do ser humano". Já o educando Guilherme acredita que "é um lugar sem poluição, sem desmatamento, um lugar limpo com ar puro".

Destacando suas considerações de meio ambiente, a educadora ressalta "tudo o que está a nossa volta: os lugares por onde passamos, que frequentamos, que vimos e tudo o que está inserido neles", concordando com a concepção do educador Pedro que comenta "meio ambiente é um espaço, seja ele natural ou construído, em que os seres estabelecem relações entre eles e com a natureza", enquanto o educador Francisco ressalta que "meio ambiente somos nós, nossa família, nosso trabalho, enfim, tudo que faz parte da nossa vida.

Já a educadora Michele acredita que "o primeiro meio ambiente e na minha opinião, também o mais importante, é o "interior" do ser humano, é lá que tudo começa, os demais ambientes são reflexos deste".

Além dessas colocações, a vida, a natureza e tudo aquilo que nos rodeia, são as concepções de meio ambiente mais citadas pelos educandos e educadores.

Através disso podemos compreender que cada indivíduo possui sua concepção de meio ambiente. Principalmente os educandos relacionam o meio ambiente apenas com o meio natural, sem considerar as relações sociais e muitos deles salientam ainda que a presença humana não faz parte do meio ambiente. Já os educadores, ressaltam as relações sociais e principalmente 0 ser humano como parte integrante do meio ambiente. 


\section{Importância da abordagem da Educação Ambiental}

A presente temática corresponde à questão da entrevista que instigava os educandos e os educadores quanto suas considerações sobre a importância da abordagem da educação ambiental nas aulas.

Com relação a isso, a educadora Janaina afirma considerar a abordagem desses temas extremamente relevantes "meus alunos são terra fértil para o plantio de um futuro sustentável, procuro mostrar a importância vital do resgate e conservação do meio ambiente". A educanda Camila salienta "a escola é o melhor lugar para aprendermos mais sobre o meio ambiente", concordando com Carla que fala "acho muito importante porque eu posso saber como preservar, para não prejudicar o meio ambiente agora e no futuro".

A educadora Ana Carolina também lembra "é importante trabalhar junto com os alunos a Educação Ambiental, para que se tornem jovens/adultos conscientes e que saibam que somos responsáveis pelo planeta em que vivemos e que deixaremos para as próximas gerações". O educando Lorenzo também destaca "gosto de estudar o meio ambiente nas aulas, porque isso ajuda a melhorar nossas ações".

Já a educadora Joana lembra "é tendo consciência de que todo o ser humano também é parte integrante e atuante do meio em que vive que os alunos poderão ter a opção de transformá-lo para melhor, por isso é tão importante a abordagem da Educação Ambiental no ensino".

Diferente de todos os outros educandos, Jaqueline e Marcelo não gostam quando temas relacionados ao meio ambiente são estudados em aula, pois acham o assunto chato.

Assim, entendemos o quanto os educadores reconhecem a relevância da Educação Ambiental e a importância de sua integração ao ensino. Os educandos, em sua maioria, revelam ter gosto pelo estudo de temas relacionados ao meio ambiente e também admitem a importância da Educação Ambiental, entretanto não discutem suficientemente sobre essa questão, fazendo nos entender que esse tema pode não ser devidamente problematizado nas aulas.

\section{Percepções e medidas apontadas pelos educandos}

Após visualizarem imagens que mostravam a degradação antrópica do meio ambiente em Rio Grande, os educandos expressaram suas percepções e medidas para reverter tais situações.

Em relação à percepção dos educandos frente às imagens, todos eles ficaram surpresos com tamanha destruição. Mesmo sendo imagens que mostram situações comuns na cidade e na vida deles, se mostraram totalmente em desacordo com ações que degradam o meio ambiente. Como comenta o educando Arthur "achei muito desumano porque o homem não está matando 
apenas vidas e florestas, mas também a si mesmo", da mesma forma, Luana afirma "as imagens mostram como o ser humano vem destruindo a natureza".

Já a educanda Marina destaca "são imagens tristes, mostram o quanto a poluição, o tráfico de animais, a contaminação das águas e muitas outras coisas, são ruins para natureza e para nós, pois estamos muito ligados a ela".

Quanto às medidas e ações apontadas pelos educandos para reverter e/ou melhorar a realidade mostrada pelas imagens, Marina também comenta "todos nós podemos fazer coisas para mudar isso, como deixar de jogar lixo nos rios e nas ruas, não cortar as árvores, não colocar passarinhos em gaiolas e etc, se todos nos unirmos por essa causa mudaremos o mundo". O educando Wesley destaca "eu posso falar para as pessoas que fazem essas coisas parar de fazer e colaborar com quem não faz e vou estar ajudando o meio ambiente".

A educanda Márcia manifesta as possíveis ações "pensando, reeducando, reutilizando, reciclando, não caçando animais silvestres e não cortando árvores". Concordando com Carla que conclui "as imagens são um absurdo, todo mundo poluindo e desmatando a natureza, isso é horrível para eles e para nós porque o meio ambiente é nossa vida e se a gente não cuidar dele, vamos estar nos prejudicando também".

Já o educando João, não sabe qual atitudes pode tomar para melhorar as situações apresentadas. Enquanto Vitória destaca "acho que sozinha, não adianta fazer nada, pois é apenas uma colaboração", concordando com o que Marcelo fala "não posso fazer nada, o que adianta eu fazer, se ninguém mais faz?". Dentre as medidas mais citadas, destacam-se "não jogar lixo" e "não desmatar".

A partir desses apontamentos, percebemos que todos os educandos discordaram das imagens que mostravam os constantes impactos causados pelo homem à natureza, mostrando-se indivíduos conscientes e críticos. Além disso, a maioria deles exemplificou uma série de medidas que poderiam ser tomadas por todos para ajudar a reverter a atual situação e evitar que as agressões ao meio ambiente continuem, indicando suas atuações como cidadãos.

\section{Situações e contexto em que é abordada a Educação Ambiental nas práticas educativas}

A atual temática está relacionada aos questionamentos feitos aos educadores quanto ao momento e ao modo que a Educação Ambiental é abordada em sua aula/escola.

Quando se tratando do momento em que a Educação Ambiental é abordada nas aula/escola a educadora Janaína afirma "Todos os dias tento tratar a educação ambiental em minhas aulas, pois o ambiente escolar é o meio de docentes e discentes que também necessita de cuidados e preservação". 
O educador Pedro destaca "Os temas ambientais são considerados temas transversais, sendo assim, devem ser abordados de forma interdisciplinar, como um fio condutor que organiza as práticas pedagógicas das diferentes disciplinas do currículo". Já a educadora Ana Carolina ressalta "Na escola ou dentro da sala de aula, nós como educadores tratamos desse tema sempre, pois é muito importante e amplo, além disso, sempre surge na mídia, motivando assim os educandos".

Dialogando sobre sua prática a educadora Joana salienta "Como trabalho com educação física, esse assunto acontece como conversa, conscientização em cuidar do espaço em que estamos, cuidando do seu corpo e o do outro, os relacionamentos nos jogos, os alimentos e água que precisamos para uma boa atividade física e o cuidado com a natureza em geral”.

A educadora Michele ressalta "Sempre que surgem oportunidades, o tema educação ambiental é discutido, dialogando e trocando idéias com os alunos", enquanto o educador Francisco afirma "Em sala de aula diariamente trabalhamos a educação ambiental, através do cuidado com o corpo, com o material, com a sala de aula e com o relacionamento aluno/aluno, aluno/professor".

Em relação à maneira como a Educação Ambiental é abordada nas aulas, o educador Pedro afirma "A educação ambiental precisa ter relação direta com vida das pessoas, caso contrário, no âmbito escolar, não se efetiva".

Já a educadora Ana Carolina explica "Às vezes o tema "Educação Ambiental" é trabalhado em um trimestre inteiro, orientado pela supervisão, em outros casos surgem relacionados aos conteúdos, e mesmo não sendo tema principal acredito que ele permeia o cotidiano em todas as disciplinas".

A educadora Joana destaca "Sempre faço relações dos temas ambientais com o cotidiano dos alunos, pois se isso não acontecer não tem significado nem objetivo, não adianta falar em meio ambiente como um slogan de moda, esse assunto deve ser levado muito a sério".

Explicando a abordagem de Educação Ambiental, a educadora Maria ressalta "Acredito que não é difícil trabalhar a educação ambiental nas aulas, pois a maioria dos conteúdos (Geografia, História, Ciências) envolve as questões ambientais". Enquanto a educadora Paula acrescenta "Na maioria das vezes converso com as turmas sobre educação ambiental dentro de conteúdos, através de textos e em assuntos que surgem pelos alunos".

Concluindo seus apontamentos, a educadora Michele salienta "Sempre que possível, faço conexões entre os conteúdos escolares e questões ambientais". Concordando com o que a educadora Janaína afirma "Até mesmo uma folha de papel mal utilizada ou jogada no chão serve de "link" para o assunto".

Percebemos que as considerações e apontamentos dos educadores 
ambiente escolar foram semelhantes em suas falas. A maioria deles afirma abordar a EA sempre que possível em suas aulas, não especificando o real momento. Além disso, revelam tratar o tema constantemente trazendo relações com os conteúdos e com o dia-a-dia dos educandos.

\section{Considerações}

Quando iniciamos o estudo, nossos objetivos eram compreender como e quando a educação ambiental é abordada no ensino das diversas disciplinas, perceber se são tecidas relações entre a educação ambiental, a realidade vivida pelos educandos da escola em questão e os conteúdos escolares e discernir em que medida a educação ambiental pode servir como aspecto desencadeador para uma tomada de consciência e de novas atitudes. Através da leitura de idéias de alguns teóricos e da investigação da narrativa de educadores e educandos percebemos que nossos objetivos foram alcançados.

Os autores nos sugerem a abordagem da Educação Ambiental como um tema transversal de todas as disciplinas, assim como nos mostram os PCN. Entretanto, somente um educador que participou dessa pesquisa apresenta essa concepção, os demais educadores argumentaram tratar a EA como um assunto de grande importância e sempre que possível em suas aulas não especificando a forma e o momento da abordagem.

De acordo com os pressupostos teóricos recorridos, a Educação Ambiental pode estar presente em todas as disciplinas quando analisa temas que permitam enfocar as relações entre a humanidade e o meio e deve enfatizar o estudo do meio ambiente onde vive o educando e a educanda, procurando levantar os principais problemas cotidianos, e fazendo associações com os conteúdos escolares. Assim, também nos dizem os educadores, que se fizeram sujeitos dessa pesquisa, quando explicam trazer a EA constantemente relacionada com os conteúdos e com a realidade dos educandos. Porém, esses educadores não apontaram quais aspectos desencadeadores permitem que essa relação seja tecida.

Tendo em vista as contribuições dos teóricos consultados, a Educação Ambiental se destaca por ser uma educação política, que não se compromete apenas com as temáticas ambientais, mas também com a ampliação da cidadania, da liberdade, da autonomia e da intervenção direta dos cidadãos e cidadãs na busca de soluções e alternativas que permitam a convivência digna e voltada para o bem comum. Logo, ao analisar as falas e a reação dos educandos frente às imagens de destruição da natureza mostradas durante a pesquisa, percebemos o quanto eles se preocupam com suas próprias atitudes, buscam soluções para mudar a triste situação ambiental do planeta e se surpreendem com a degradação ambiental explicitada nas fotos, mesmo sendo a maioria delas dos arredores da escola. Além disso, compreendemos que a EA precisa ser mais discutida e problematizada na prática, através de questionamentos reconstrutivos, tornando o conhecimento desses educandos mais complexos. 
Durante o estudo, também levantamos algumas hipóteses: a EA é um tema de real importância na percebida construção de conhecimentos e na formação de cidadãos conscientes e deve ser percebida dessa forma pelos educadores; a abordagem da EA como sugerem os PCN, como tema transversal, possibilita uma maior discussão desse tema e contribui para a construção de uma aprendizagem significativa; a visão dicotômica entre ser humano e ambiente se faz presente no âmbito escolar; os educandos têm gosto pelo estudo de temas relacionados ao meio ambiente e a sua preservação.

Ao encontrarmos respostas para essas discussões, por vezes na bibliografia ou nas narrativas dos sujeitos da pesquisa, compreendemos que através do estudo, nossas hipóteses foram confirmadas.

Como pudemos distinguir na fala dos educadores, a Educação Ambiental têm espaço garantido em suas práticas pedagógicas e segundo seus apontamentos, ela contribui amplamente para a formação cidadãos conscientes e críticos. Entretanto, percebemos também, que ao falar de Educação Ambiental, em grande proporção são feitas relações apenas com as questões ambientais e ecológicas e pouco se problematiza as relações políticas, econômicas, sociais e culturais entre a humanidade e a natureza e entre os seres humanos.

Em relação à abordagem do meio ambiente como tema transversal de todas as disciplinas do currículo, sugerida pelos PCN, se faz necessário recordarmos que os autores os criticaram, não por seus objetivos, mas sim por utilizar a palavra transversalidade como sinônimo de interdisciplinaridade e essas têm significados distintos. Entretanto, os teóricos não negaram a importância desse documento educacional, por marcar formalmente a inclusão da Educação Ambiental brasileira como integrante de todas as disciplinas. Sendo tratada dessa maneira, são possíveis discussões mais complexas do assunto, sob diversos ângulos e relacionadas aos diversos conteúdos, assim os educandos podem tecer um rede de significados, possibilitando que a aprendizagem e a construção do conhecimento seja um processo dinâmico.

Mesmo sendo esse assunto tão discutido e difundido no meio teórico, somente um educador mencionou a transversalidade como modo de abordagem da EA em sua prática, sendo que esse é mestrando em Educação Ambiental. Os demais educadores salientaram abordar a EA em vários momentos de sua aula, dando grande atenção a esse tema, porém, não têm conhecimento de sua abordagem como tema transversal. Com isso, compreendemos que a Educação Ambiental é uma temática pouco discutida durante a formação inicial, sendo necessários espaços de formação continuada para que o tema seja devidamente concebido e problematizado.

Quando recorremos à bibliografia para conceituar o meio ambiente entendemos que não há um consenso quanto essa definição. Porém, o autor consultado salienta que meio ambiente não é apenas sinônimo de meio natural, mas sim um lugar determinado e/ou percebido onde estão em relação dinâmica 
e em constante interação os aspectos naturais e sociais. No entanto, os mesmos autores ressaltaram que o ser humano vive atualmente grandes dicotomias, dificilmente se considera parte integrante do meio ambiente em que vive, mas comumente seu observador e explorador, não levando em conta suas constantes relações sociais, culturais e biológicas com a natureza. Logo, essa segregação entre ser humano e natureza, também foi percebida quando questionamos os educadores e educandos durante o estudo sobre suas concepções de meio ambiente. Dentre os apontamentos citados pelos sujeitos da pesquisa, poucos foram aqueles que se incluíram como parte do meio ambiente. Os demais consideravam o meio ambiente como a natureza, os animais, as plantas, as paisagens verdes, não levando em conta as relações sociais e a presença integrante do homem na natureza.

Também pudemos confirmar que os educandos realmente gostam quando as temáticas relacionadas à educação ambiental estão presentes nas aulas. Durante a pesquisa ressaltaram que a temática é muito importante e seu estudo é prazeroso, com exceção de dois educandos que consideram o tema chato. A maioria deles mostrou-se preocupada com as questões ambientais e com suas atitudes frente à atual situação ambiental do planeta. Entretanto, não discutiram suficientemente sobre essa questão, fazendo nos entender que esse tema pode não ser devidamente problematizado nas aulas. É necessário salientar ainda, que sendo esse um tema considerado agradável pelos educandos, a receptividade e o bom êxito de práticas que envolvam a Educação Ambiental são garantidos.

Portanto, discernimos durante o estudo a resposta para nossas indagações iniciais: como a EA é realmente abordada no ambiente escolar? São tecidas relações entre EA e os conteúdos escolares na prática? Como os alunos procedem diante de tais práticas que envolvam sua atuação cidadã frente às temáticas socioambientais?

Dentre os problemas enfrentados durante a realização desse trabalho, destacamos que muitos educadores pensaram que iriam ser julgados e/ou avaliados, por isso se recusaram em responder a entrevista e participar da pesquisa.

Mesmo com tantas afirmações e respostas para os questionamentos, restaram algumas dúvidas ao longo do estudo. Ainda nos perguntamos se realmente a EA está constantemente presente e efetiva na prática dos educadores participantes da pesquisa. Já que, a atual pesquisa se baseou em entrevistas e não em uma observação, assim sendo, não podemos afirmar que as colocações dos educadores se efetivam na prática. 


\section{Referências}

BRASIL, Ministério da Educação. Parâmetros Curriculares Nacionais. Secretaria de Educação Fundamental. Brasília: MEC/SEF, 1998.

CARVALHO, I,C.M. Educação ambiental: a formação do sujeito ecológico. São Paulo: Cortez, 2006.

LOUREIRO, C.F.B. Trajetória e Fundamentos da educação ambiental. São Paulo: Cortez, 2006.

MINAYO, M.C.S. Trabalho de Campo: contexto de observação, interação e descoberta. In: DESLANDES, S.F. (Org.). Pesquisa Social: teoria, método e criatividade. Petrópolis, RJ: Vozes, 2011.

REIGOTA, M. O que é educação ambiental. São Paulo: Brasiliense, 2009. 